This is a postprint version of the following published document:

Corcoba Magaña, V., Muñoz-Organero, M. Artemisa: a personal driving assistant for fuel saving, IEEE Transactions on Mobile Computing, (2016), 15(10), pp. 2437-2451. Doi: https://doi.org/10.1109/TMC.2015.2504976

(C) 2015. IEEE. Personal use of this material is permitted. Permission from IEEE must be obtained for all other uses, in any current or future media, including reprinting/republishing this material for advertising or promotional purposes, creating new collective works, for resale or redistribution to servers or lists, or reuse of any copyrighted component of this work in other works. 


\title{
Artemisa: A Personal Driving Assistant for Fuel Saving
}

\author{
Víctor Corcoba Magaña and Mario Muñoz-Organero, Member, IEEE
}

\begin{abstract}
In this paper, we propose a driving assistant that makes recommendations in order to reduce the fuel consumption. The solution only requires a smartphone and an OBD/Bluetooth device. Eco-driving advices try to avoid situations that cause an increase in the fuel consumption such as inappropriate speed or slow reaction to the detection of traffic signs and traffic incidents. The main contribution of this paper is the use of artificial intelligence techniques in order to issue the eco-driving tips that are best adapted to the user profile, the characteristics of the vehicle, and the road state conditions. This is very important because the driver may lose the interest due to the high requirements that tend to be provided by general use eco-driving assistants. In order to property assess and validate the proposed solution, it has been implemented on several Android mobile devices and has been validated using a dataset of 2,250 driving tests using three different models of vehicles with 25 different drivers on three distinct routes. The results show that the system reduces the fuel consumption by 11.04 percent on average and even, in certain cases, the fuel saving is greater than 15 percent.
\end{abstract}

Index Terms-Intelligent vehicle systems and telematics, eco-driving, fuel optimal control

\section{INTRODUCTION}

$\mathrm{T}$ HE vehicle is one of the most significant innovations of the past century. Its invention has had a huge impact at the social, ecological, and economic levels. The expansion of the automobile has contributed to globalization and economic growth in Europe, United States, Japan and many other parts of the world. It has also helped the expansion of suburban areas. However, it has caused many negative effects both at the social [1] and at the environmental levels [2]. This work is mainly focused on the environmental level.

The increase in the number of vehicles in circulation is responsible for the destruction of green spaces that have been transformed into roads. On the other hand, vehicles tend to use combustion engines that emit polluting gases when they burn fuel in order to obtain traction power. These emissions are responsible for the greenhouse effect (CO2), acid rain (SO2, NOx), as well as the proliferation of certain lung diseases such as lung cancer [3]. Moreover, the fuel used by these engines is a scarce and expensive resource whose extraction has an important impact on the environment too.

In order to reduce the impact of vehicles on the environment it is necessary to minimize the demand for fuel, which causes pollution when is burned. Solutions to save fuel can be categorized into two groups:

Technology-based solutions. Manufacturers have introduced several improvements to comply with regulations regarding the emission of polluting gases. In addition, the increase in the price of fuel has made that drivers show a growing interest when they purchase a vehicle.

Solutions based on the driver (eco-driving and eco-routing). Driver behavior affects fuel consumption significantly. The softening of the driving style, the proper control of speed patterns, the proper use of air conditioning or the choice of the route are factors that influence both the fuel consumption and the trip safety. This work is focused on these techniques for fuel saving.

\subsection{Our Approach and Main Contributions}

In this paper, we propose an eco-driving assistant to support the driver in order to change the driving style by one more efficient that takes into account the driver style, the road conditions and the type of vehicle, enhanced by using game mechanics and dynamics techniques. In addition, the proposal provides information about the environment in advance in order to avoid inefficient actions.

The main contributions of this work are:

Advices are fitted to the driver's driving profile: Other solutions do not take into account the previous driving style of the driver and propose an abrupt change. The driver feels frustration because he or she fails the objectives. Therefore, users stop using the system.

It offers anticipatory advices. Most of the driving assistants are limited to assess the driving and issue advice when the driver performs inefficient actions such as sudden accelerations or shift gears too late. However, our proposal has the following tips:

- Prediction of the driver behavior on regular routes and alerts to the user in order to adjust the vehicle speed, avoiding inefficient driving.

- Detection of traffic incidents.

- Optimum Average Speed 
- Optimum Speed Profile

- Recognition of traffic signs. The solution provides the user an optimal deceleration pattern when the vehicle is approaching a traffic sign that forces them to stop such as stop or yield.

The proposal in this paper uses gamification tools to encourage that the driver follows the recommendations and completes the objectives. Other driving assistants are limited to show a score or the fuel economy. We have defined a set of achievements. They are used to promote the adoption of a particular driving behavior that minimizes the fuel consumption.

The installation of hardware in the vehicle is not required and the cost is kept low. We only need an Android mobile device and an OBD-Bluetooth adapter.

A total of 25 drivers who have used the proposal in this paper regularly have validated it in a real environment. Previous driving assistants tend only to be validated in simulators. These solutions need information that is not available in real environments or require the installation of sensors on the road. In our case, the algorithms implemented are using information which can be easily obtained. No special infrastructure is required.

\section{Related Work}

The benefit of adopting an efficient driving style has been widely tested in different works. Drivers have been able to save between 10 to 25 percent of fuel [4], [5]. However, users need to have knowledge, skill, and motivation. Knowledge can be obtained through eco-driving lessons or driving assistants. The authors in [6] evaluated the impacts of an eco-driving education session on the energy and environmental performance of a group of drivers as well as the changes on their driving patterns. The results showed an average improvement of 4.8 percent in fuel consumption. In [7] the authors combined eco-driving lessons with individualized feedback based on their results. The study was conducted by 15 participants who achieved to decrease $1.7 \mathrm{~kg}$ of $\mathrm{CO} 2$ per vehicle per day Another strategy is to use efficient driving assistants in order to change the driving habits. The simplest assistants are designed to provide instantaneous fuel rate and $\mathrm{CO} 2$ emissions information, also advising on acceleration/braking rates [8], [9]. Reference [10] proposes a method based on partial theoretical models that calculate the optimal cruising speed for the vehicle, taking into account the engine characteristics and basic physics-dynamics rules.

In addition, even in the case in which a driver drives efficiently, the driving assistant can help to reduce fuel consumption if it provides information about the environment in advance. On many occasions, the driver makes mistakes because he or she does not have enough information about the environment in order to be able to anticipate forthcoming situations. The authors in [11] propose the use of model predictive control of a vehicle in a varying road-traffic environment for ecological driving based on anticipation of the road and traffic in a crowded road network regulated by traffic signals. The authors in [7] propose a system to provide real-time advice based on changing traffic and infrastructure conditions by adjusting the speed of the vehicle if 2 the information of the timing in upcoming traffic lights is known. In [12], the authors analyzed the impact of an Anticipatory Eco-Driver Assistant System (ADAS) in different complex driving situations on the driver behavior. They found a significant fuel reduction with the ADAS (between 9 and 15 percent). Furthermore, authors concluded that there was not a relationship between the complexity of the scenario and the percentage of fuel saved.

Moreover, there are several studies that have observed over time some deterioration in fuel efficiency [13] because drivers return back to their previous bad driving habits. Driving is a very complex activity in which the driver has to perform multiple tasks at the same time, so it is usual that the driver forgets about fuel economy when driving. Continuous feedback is necessary. One way to motivate the user to save fuel is by adding gamification techniques to eco-driving assistants.

Gamification consists of building a game in a non-game context to perform arduous and repetitive activities. This improves the engagement of the user. In [14], we can see a review about gamification and the impact on teaching. There are many scenarios where this concept is applied. For example in [15], authors used emoticons and sounds to encourage the recycling of bottles. When a user throws away a bottle in the garbage, the emoticon smiles. They conclude that the proposed system increases the recycling rate by a factor of $x 3$. In [16] the authors propose an application to report road accidents. The application uses a game layer to motivate drivers to use it and make it more fun. Another example is INNOV8 [17]. INNOV 8 is a game developed to teach new employees the IBM Business Process Management. This software tool trains employees without spending money on transportation for a teacher. Besides, the results are even better than those obtained with traditional methods.

\section{OVERVIEW OF ECO-Driving AsSistant}

Eco-driving [21], [22] is a very useful method to reduce the fuel consumption since it is independent of the type of the vehicle and its age. However, of its major challenges are that it is very difficult to change driving habits. In addition, even if the driver temporally improves him or her driving style when learning eco-driving techniques, it tends to return to his or her previous driving habits over time if not properly motivated.

An eco-driving assistant is proposed in order to solve these problems. The aim is to facilitate the learning of this driving technique and providing information in advance to avoid inefficient actions. Motivation is also taken into account by using gamification techniques. Fig. 1 shows an overview of the proposed solution. The proposal is run on an Android Smartphone. In addition, an OBD/Bluetooth adapter is required to obtain the telemetry.

The assistant monitors the driving and the environment. Input Data (vehicle telemetry, weather, slope, road pictures, etc.) are analyzed using different algorithms of artificial intelligence:

- EM Clustering Algorithm: It retrieves information based on a certain criterion [23]. For example, vehicle telemetry where fuel consumption provided by the manufacturer is $61 / 100 \mathrm{~km}$. It is used to customize 


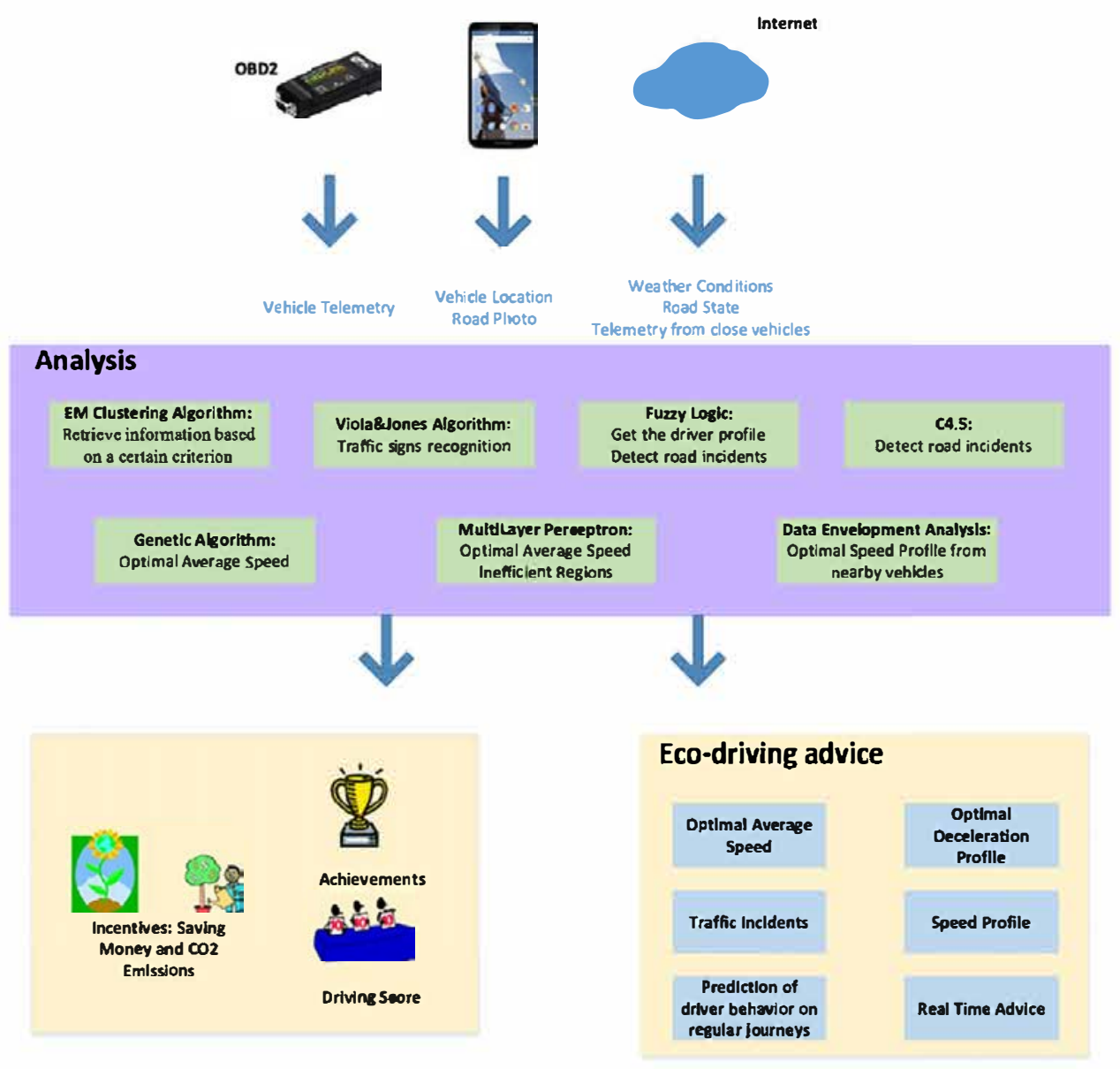

Fig. 1. Overview of the eco-driving assistant.

the real time eco-driving advices and to choose the driving samples from the training database (algorithms to estimate the optimal average speed and improve the driving in inefficient regions).

- Fuzzy logic: It is used to evaluate the driving from the point of view of energy efficiency [24].

- Genetic Algorithm and Multilayer Perceptron: They are employed to estimate the optimal average speed for each segment of a route [25].

- Nä̈ve Bayes and C4.5 Algorithm: They detect unusual events such as traffic accidents or traffic jams based on vehicle telemetry.

- Viola $\mathcal{E}$ Jones algorithm: It is used to recognize static vertical recognize traffic signs [26].

The result of data analysis is a set of eco-driving tips and feedback to motivate the user in order to save fuel. Eco-driving advices can be classified into two groups: Preventive tips and post-action tips. Eco-driving advices based on anticipation save a lot of fuel because they help the user in order not to make inefficient actions. The key in order to build an optimal eco-driving system is anticipation since it allows reducing the frequency and intensity of the accelerations (positive and negative). On the other hand, post-action tips warn the user in order not to make mistakes again in the driving.

In summary, the assistant provides the following eco-driving tips:

\section{Preventive tips}

- Optimal Average Speed for a road section

- Best Close Driver

- Optimization of the driving in inefficient region on habitual journeys

- Traffic Incidents

Post-action tips

- Real-Time Advices

On the other hand, motivation systems are very important to ensure that the user does not lose interest and comply with the eco-driving tips. In our case, we use the technique called "gamification". This method consists of using elements of games (such as scoring, achievements, and challenges) in a different context in order to motivate the user to perform difficult or complex tasks.

The eco-driving assistant evaluates the driving when the user finishes the trip using fuzzy logic. The score is a number between 0 and 10. A high score means that the user is following the recommendations of the assistant. This value is used to build a ranking where users are sorted according to their energy efficiency.

In addition, both while a driver is driving and once the trip is completed, the driver can unlock achievements. The idea is to encourage the user to overcome specific targets affecting fuel consumption. For example, the acceleration 3 does not exceed $2.5 \mathrm{~m} / \mathrm{s}^{2}$ on the whole trip. 
Finally, we used different incentives such as CO2 or saving money in order to encourage the user to change driving style. The incentives were chosen taking into account their previous driving profile.

In the following sections, we are going to describe each of the elements of the system. The proposed algorithms have been validated on three different routes (Spain). Routes have urban roads, highways, and secondary roads.

\section{Data Acquisition System}

The Data Acquisition System obtains the value of all variables that influence fuel consumption or that can help to predict the actions to be performed by the driver to save fuel. It uses as information sources the following means:

- Internet: Road (traffic, incidents) and weather conditions [34], [35].

- Camera: Traffic Signs Detection.

- GPS: Vehicle Location.

- OBD2: Vehicle speed, engine speed, engine load, mass air flow, throttle position, and travel distance.

Others variables such as accelerations and decelerations are estimated from the vehicle speed. We employs this solution because the signal from gyroscope has noisy and we will have to apply filters that increases the response time unnecessarily.

In modern vehicles, data obtained from the vehicle sensors are sent to the control units (ECUs) through buses such as: CAN, MOST, LIN and FlexRay. These data can be monitored using the onboard diagnostic port (OBD). This port was proposed in 1984 to assess the emission of pollutant gases. An improved version which was called OBDII was presented in 1988.

This new version of the OBD port allows us to check more variables. In addition, it standardizes the type of connector (SAE J1962), the number of pins, electrical signaling protocols and the message formats. Unlike OBDI, it does not require external power. The aim of OBDI was to evaluate the emission of gases. However, OBDII also intended that we can make a diagnostic in depth. We may obtain information such as: vehicle speed, engine speed, engine load, and so on. This port is mandatory in the United States since 1997, and in Europe since 2003.

We plug an OBDII/Bluetooth adapter on OBD port in order to get the vehicle telemetry. This device establishes a connection with an Android mobile device. When we want to get the diagnostic values, the Android mobile sends a message with a code called PID (on-board diagnostics Parameter IDs). The PID code indicates the variable that we want to check. The OBDII/Bluetooth adapter sends the message to the broadcast address on the vehicle bus. For example, if we want to get the vehicle speed, the mobile device should send to the bus a message with the PID code "OD". When an engine control unit (ECU) connected to the bus recognizes the code, it builds a response message. The response message includes the value of the variable that we want to monitor and the ECU address in order to establish a direct connection. The OBDII/Bluetooth adapter receives the message and sends it to the Android mobile who is responsible for decoding it.
The sampling rate of the sensor readings is one per second in all cases (GPS and OBD), except in the camera. In this case, it depends on the smartphone. The system is able to operate at nine frames per second on a Samsung Nexus $S$ smartphone, detecting static traffic signals up to 20 meters in advance (detected traffic signals are fed into central a database in order to improve the anticipation capabilities of the system in future occasions).

\section{Preventive Tips}

\subsection{Optimal Average Speed}

Speed has a strong influence in the number and intensity of the accelerations. The driver has to accelerate and slow down when the vehicle speed is not appropriate taking into account the road conditions.

During acceleration, the demand of energy significantly increases since the vehicle has to overcome a force proportional to the required acceleration and the vehicle weight. In addition, if the acceleration is followed by a slowdown, energy previously required is wasted.

To adjust the vehicle speed, the eco-driving assistant provides to the user the optimal average speed, which minimizes the accelerations (positive or negative), for each route section. The optimal average speed is estimated using an algorithm based on genetic algorithms and telemetry previously obtained by other vehicles along with information about the road conditions, time, and day of the week.

The proposed solution takes into account the current state of the environment and the driving style of the driver in order to build the initial population of the genetic algorithm. The fitness function is a Multilayer Perceptron Network. This algorithm, given an average speed, estimates the median acceleration and deceleration based on an analysis of previous driver behavior and traffic conditions. The challenge is to minimize the intensity of the (positive and negative) acceleration to save fuel. In [36], the algorithm is described in more depth. Fig. 2 captures the flowchart of the optimal average speed algorithm. Table 1 shows the parameters used to run the algorithm. Table 2 captures the validation of the fitness function on route $\mathrm{A}$. This route was divided in three different road section in order to estimate the optimal average speed. The training dataset was 300 samples and the test dataset was 200 samples.

Genetic algorithm has the following stages:

Representation. The aim of the proposal is to minimize the number of accelerations and decelerations to reduce energy demand, and therefore, greenhouse gas emissions. This optimization problem is defined as a combinatorial optimization problem which is solved using a genetic algorithm. Genetic algorithms were first proposed by John Holland in his book "Adaptation in Natural and Artificial Systems" in 1975 [37].

An important aspect of such algorithms is the representation of the individual. In our case, individuals are represented as vectors. Each position of the vector contains the value of an attribute. Individuals have the following attributes:

- Average Speed on the road section.

- Standard deviation of the vehicle speed.

- Number of hard accelerations. The limit of hard acceleration depends on driver (see section Customizing the eco-driving advice). 


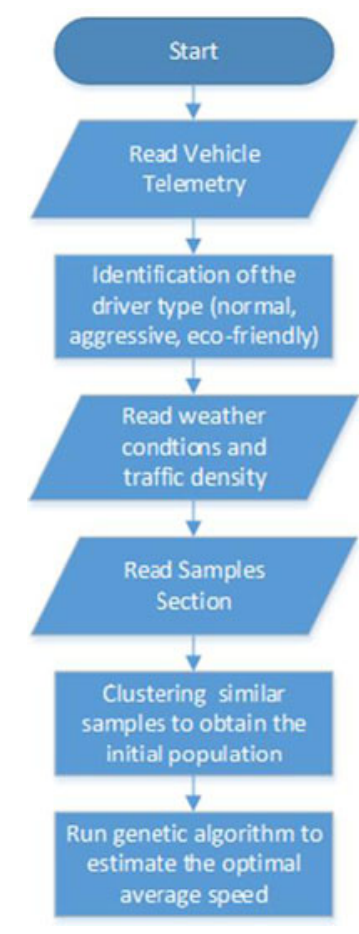

Fig. 2. Algorithm to estimate the optimal speed for each road section.

- Number of hard decelerations. The limit of hard deceleration depends on driver (see section VII Customizing the eco-driving advice).

- Positive Kinetic Energy (PKE).

- Time Trip on the road section.

Initialization. The initial population is obtained from vehicles that have previously gone through the road. Optimal average speed depends on many factors such as: traffic state, weather conditions, road type, vehicle's engine type and driving style. Therefore, some previously samples may be useless in order to estimate the optimal average speed due to its dynamic nature. To solve this problem, we propose to cluster telemetry samples taking into account:

- Time of the day/day of the week/week of the year.

- Weather conditions and road state.

- Driving style.

Selection stage: the algorithm chooses the " $k$ " individuals with best fitness. Then, it chooses " $\mathrm{t}$ " individuals with the least travel time from the " $k$ " population. Therefore, the solution will have a reasonable travel time.

Crossover stage, couples of parents are set randomly. Individuals cannot be combined with themselves. The values of the attributes of the children are calculated by using the following procedure:

TABLE 1

Parameters of Genetic Algorithm

\begin{tabular}{lc}
\hline Parameter & Value \\
\hline Initial Population & 100 \\
Selection 1 (Fitness Value) & 12 \\
Selection 2 (Trip Time) & 6 \\
Mutation Probability & 0.2 \\
Stop Condition & 60 seconds or five time without \\
& improving the fitness value \\
\hline
\end{tabular}

TABLE 2

Validation of the Fitness Function on Route $A$ (Mean Absolute Error)

\begin{tabular}{lccc}
\hline & Section 1 & Section 2 & Section 3 \\
\hline Acceleration Estimation & 0.31 & 0.20 & 0.34 \\
Deceleration Estimation & 0.11 & 0.15 & 0.09 \\
\hline
\end{tabular}

- Average speed: It is obtained by calculating the average speed of the parents.

- Number of hard accelerations (positive and negative), standard deviation of the vehicle speed, and positive kinetic energy are the values obtained in the past on the same road section by the driver.

- Time trip: it is calculated assuming that driver drives to the recommended average speed.

Mutation stage. Each child obtained in the crossover stage has a probability " $\mathrm{t}$ " of being replaced by an individual whose average speed is obtained randomly considering speed limits.

Replacement stage. New population will replace the individuals with the worst fitness from the previous population.

Stop condition. The process is repeated until there are no improvements in the fitness value after five interactions or execution time exceeds 60 seconds. Stop condition could change depending on the phone features.

\subsection{Optimal Speed Profile from Nearby Vehicles}

The proposal uses a learning method for eco-driving based on the imitation in order to the driver to improve his or her driving style from the viewpoint of energy efficiency. The solution estimates the efficiency of nearby drivers based on vehicle telemetry and notifies the user.

Vehicle telemetry, as previously presented, is obtained through the OBD2 diagnostic port and sent to an Android mobile device. Then, the mobile device sends vehicle telemetry to a central server. On the server, Data Envelopment Analysis (DEA) [38] is employed to calculate the efficiency of driving. This technique calculates the inefficiency of the driver by comparing it to nearby drivers considered as efficient. This feature is very important because other solutions that are found on literature calculated efficiency values associating the input variables with statistical averages that may not be applicable to this context due to the dynamic nature of traffic.

Data envelopment analysis is a linear programming methodology to estimate the efficiency of multiple decision-making units (DMUs) when the production process presents a structure of multiple inputs and outputs. DMU [39] is defined as the entity responsible for converting inputs into outputs and whose performances are to be evaluated. DMUs may include banks, department stores, supermarkets, hospitals, students, drivers, vehicles, and so on. A group of DMUs is used to evaluate each other with each DMU having a certain degree of managerial freedom in decision making. This method allows us to make relative comparisons. DMUs have the following features:

- Numerical data are available for each input and output. 
- The DEA elements (inputs, outputs and choice of DMUs) should show an analyst's or a manager's interest.

- The measurement units of the different inputs and outputs need not be congruent.

In our proposal, each DMU represents a different driver. The objective is to obtain the efficiency of each user. Drivers whose efficiency values are higher are those who act as models for the rest of the drivers. If we consider a set of drivers " $n$ " (DMUn), each of them with an "I" number of inputs and " $\mathrm{O}$ " number of outputs, the efficiency measure $E_{k}$ for $\mathrm{DMU}_{\mathrm{k}}$ (driver $\mathrm{K}$ ) is calculated by solving the following linear programming model.

Maximize:

$$
E_{k}=\frac{\sum_{r{ }_{1} u_{r} y_{r} k}^{O}}{\sum_{i 1}^{I} v_{i} x_{i k}}
$$

Subject to:

$$
\begin{aligned}
& \frac{\sum_{r{ }_{1} u_{r} y_{r k}}^{O}}{\sum_{i{ }_{1} 1}^{I} v_{i} x_{i k}} \leq 1 \\
& u_{r} \geq 0 ; v_{i} \geq 0
\end{aligned}
$$

where $y_{r k}$ is the selected output of each variable (e.g.: Driving time at steady time) from the driver " $K$ ", $x_{i k}$ is the selected input of each variable (e.g.: Average Acceleration) from the driver " $k$ ", and $v_{i}, u_{\tau}$ are the weight factors and are determined for each DMU. Therefore, we have to solve the linear prog ramming model " $n$ " times, once for each driver. The driver is considered to be inefficient when $E_{k}$ is less than 1. Instead, when the driver is applying the eco-driving rules $E_{k}$ is 1 .

In this algorithm, the selection of input and output parameters is very important because they directly affect the accuracy of the results. We have to identify which variables affect fuel consumption and to which extend. In our case, we have based on the longitudinal dynamics of the vehicle [40], [41]. The result of an increase in the value of these variables is independent of the vehicle type. On the other hand, sometimes it is difficult that there are vehicles with similar characteristics. For this reasons, the different car type or engine type is not considered. Alternatively, we could use Data Clustering Algorithms such as Expectation-maximization algorithm [23] before run the DEA algorithm. This algorithm would take into account the characteristics of the vehicle to build the groups. In this case, the DMUs would only be formed by vehicles belonging to the same cluster. Fig. 3 shows the mechanism to estimate the efficiency of d riving.

Input parameters:

- Average Acceleration $\left(\mathrm{m} / \mathrm{s}^{2}\right)$.

- Average Deceleration $\left(\mathrm{m} / \mathrm{s}^{2}\right)$.

- Percentage of time that engine speed is not in the optimal range.

- Positive Kinetic Energy: It is calculated using the following equation [43], [44], [45]:

$$
P K E=\frac{\sum\left(v_{i}-v_{i}\right)^{2}}{d} ; v_{i 1}<v_{i}
$$

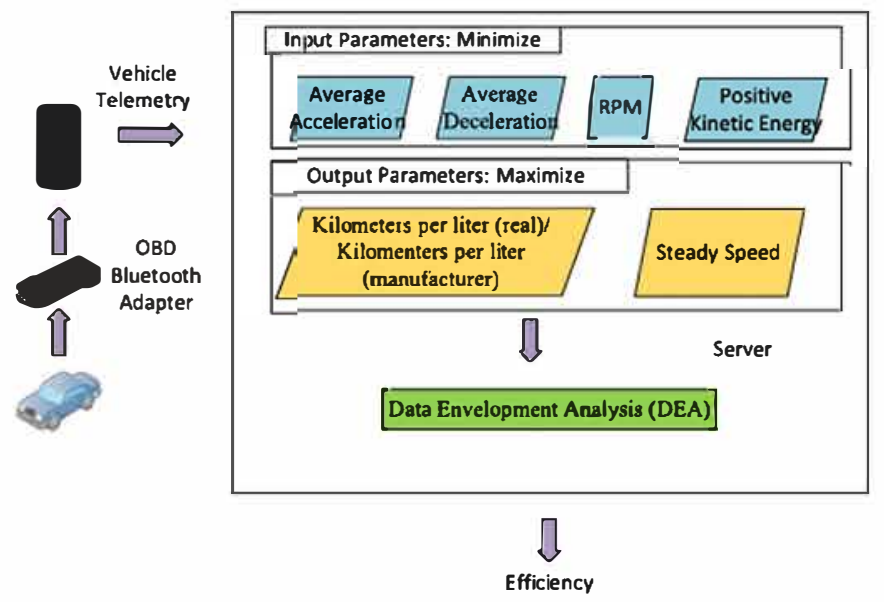

Fig. 3. Method for estimating the driving efficiency.

where $v$ is the vehicle speed $(\mathrm{m} / \mathrm{s})$ and $d$ is the trip distance (meters) between $v_{i}$ and $v_{i} \quad$.

Output parameters:

- Kilometers per liter (real)/Kilometers per liter (Manufacturer).

- Driving time at steady velocity (seconds).

To run the algorithm, we need at least one close driver. Finally, the system notifies the driver about who is the best driver from the viewpoint of energy saving and suggests that he or she imitates the best driver's driving behavior. Therefore, users can observe how they should behave in a specific situation unlike other learning systems such as ecodriving lessons. The solution provides information (registration number, color and manufacturer) about the best vehicle using the loudspeaker in order to spot and track it. At the same time, the screen of smartphone shows the average speed of the driver compared to the average speed of best driver. The aim is to provide feedback when the visibility conditions are poorly, e.g.: there is a vehicle between the best driver and us.

\subsection{Traffic Sign Detection and Optimal Deceleration Patterns}

One of the reasons for the increase in the fuel consumption on urban roads is the presence of traffic signs that may require the vehicle to reduce the speed or even to stop. These elements require the user to slow down or stop, wasting energy.

We propose a solution to reduce the impact of traffic signs on fuel consumption. The idea is to provide the user an optimal deceleration pattern when the vehicle is approaching them. The algorithm estimates the distance required to stop the vehicle without using the brakes, taking into account the rolling resistance coefficient and the road slope angle. Appropriate advice and feedback is provided to the driver in order to release the accelerator pedal. The estimated distance to stop the vehicle when travelling at a certain speed is estimated as:

$$
d_{s} \approx \frac{x^{\frac{2}{2}}}{2\left(\mu g \cos \theta\left(x_{1}\right)+g \sin \theta\left(x_{1}\right)\right)},
$$

where $x_{2}$ is the vehicle speed, $\mu$ is the rolling resistance coefficient, and $\theta\left(x_{1}\right)$ is the road slope angle as a function of 6 location $x_{1}$, and $g$ is the gravitational constant. 
The rolling resistance coefficient $(\mu)$ is dependent on a great number of parameters such as: the surface, the radius of the tire, the weight, the tire pressure, the temperature and the speed. However, we can estimate the coefficient using the following equation:

$$
\mu=\frac{k}{100}\left[5.1+\frac{5.5+9 p}{p n}+\frac{8.5+3 p}{p n} *\left(\frac{v}{100}\right)^{2}\right]
$$

where $k$ is a coefficient dependent on the type of tire ( 0.8 for radial tires and 1 for diagonal tires), $p$ is the weight per tire $(\mathrm{t}), p n$ is the tire pressure $\left(\mathrm{Kg} / \mathrm{cm}^{2}\right)$ and $v$ is the vehicle speed $(\mathrm{Km} / \mathrm{h})$.

The solution uses the mobile device embedded camera to recognize the following types of static traffic signs:

- Yields

- Pedestrian crossing

- Stop.

The image captured from the camera is pre-processed $10 \times$ using cubic interpolation. Due to the limited processing capabilities on mobile devices, only the right half of the image (where the traffic signals are first detected if driving on the right side of the road) is pre-processed. The system is able to operate at nine frames per second on a Samsung Nexus S, detecting static traffic signs up to 20 meters in advance. This distance is very short. Detected traffic signals are fed into central a database in order to improve the anticipation capabilities of the system in future occasions. Using the information of previously detected traffic signals makes the system able to provide appropriate advice before the signs are detected. Reference [42] describes the solution in more depth.

Viola and Michael [26] is employed in order to recognize the traffic signs. It is based on a cascade of strong classifiers. The set of classifiers is first built using an external PC system and the result is then transferred to the Android mobile device as an $\mathrm{xml}$ file. The efficiency of this algorithm is due to the use of features instead of pixels, the integral representation of the image, and the use of a cascade of weak classifiers. The features of an image are calculated as the difference of the sum of two or more rectangular areas adjacent pixels. The integral representation of the image allow us to calculate quickly the features. The integral image is the same size as the original image. However, each point of the image is calculated as the sum of the pixels above and in the left. This method allows to calculate the value of any rectangular sum at constant time. The number of features is very high. To resolve this problem, the authors propose to use a modification of the Adaboost algorithm. The idea is to use a set of classifiers sorted by complexity and arranged in cascade. The first classifier (the less complex) processes all the sub-windows of the integrated image. The sub-windows discarded by this first classifier are not processed again in the following stages. The same happens when running the rest of classifiers. In this way, classifiers with greater complexity only process a small subset of sub-windows. The algorithm works very well because the majority of the subwindows do not contain the object that you want to detect.

We built three classifier, one for each type of traffic sign (yield, pedestrian crossing, and stop). For each classifier, we 7
TABLE 3

Validation of Viola \& Jones Algorithm for Recognizing Traffic Sings

\begin{tabular}{lccc}
\hline Traffic sign & Hits & Misses & False Positives \\
\hline Yield & $81.52 \%$ & $18.48 \%$ & $11.2 \%$ \\
Stop & $83.45 \%$ & $16.55 \%$ & $11.89 \%$ \\
Pedestrian Crossing & $76.17 \%$ & $23.83 \%$ & $9.34 \%$ \\
\hline
\end{tabular}

employed 1,000 positive images in order to train the classifier. Each positive image contained a cropped traffic sign normalized to the size of $24 \times 24$. 3,500 images were used as negatives. We build the classifier using OpenCV. It is an open source library of computer vision which is available for all major operating systems (IOS, Android, Windows, OS X, and Linux). We run it with the following configuration:

- Minimum hit rate per stage: 0.995

- Maximum false positives per stage: 0.5

- Number of stages: 30 .

The classifiers were tested with a set of 500 images. Images from the test set were taken using different cameras and under several different lightning conditions. Table 3 shows the results.

\subsection{Inefficient Regions}

During tests, we have observed that drivers tend to make mistakes at the same places from the point of view of energy efficiency in usual routes.

The proposed eco-driving assistant issues advice in order to optimize the fuel consumption on regular routes taking into account the detection of inefficient regions where the user tends to waste energy. The idea is to find out in which areas a driver usually realizes inefficient actions from the point of view of energy consumption. The proposal alerts the user in advance in order to adjust the vehicle speed or change gears, avoiding inefficient driving.

To detect inefficient areas, the system uses vehicle telemetry: acceleration, deceleration, engine speed, engine load and vehicle speed. A fuzzy logic system determines whether the driver drove efficiently or not in a region. Section 7 describes the driving evaluation in more dept. Now, we have to group them by location, since it is possible that there are many nearby points. The idea is to split the route into areas. The warning assistant predicts if the user will drive inefficient when approaching an area. Expectation-maximization (EM) algorithm is used in order to group the labeled driving samples on regions.

Sometimes there are events on the road that force the driver to make inefficient actions, for example: when a pedestrian crosses the road without respecting traffic signs. These incidents could generate false alarms. A filter is applied to the samples to avoid this problem. When the number of inefficient driving samples is low in a region, we assume that the driver probably drove inefficiently due to a particular (not regular) state of the environment. Therefore, we do not consider that area.

Finally, when the driver drives in the same route, the system predicts if the driver will return to a similar inefficient driving pattern in the nearby region. The algorithm multilayer-perceptron is used to perform the prediction. 


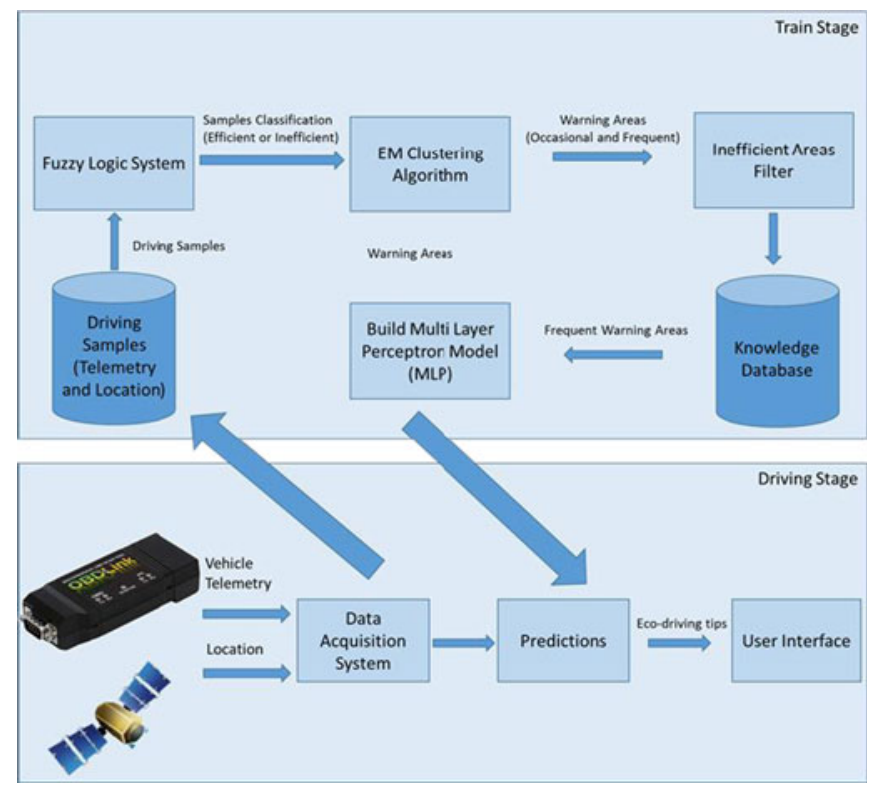

Fig. 4. Algorithm for optimizing usual routes.

The input variables are: median value of accelerations, decelerations, engine speed, engine load and vehicle speed, number of accelerations, traffic density, stop time, and positive kinetic energy. The output is the probability that the driver will perform inefficient actions. If this value is high, the system warns the user. Therefore, the driver can take the appropriate action.

Fig. 4 shows a schema of the solution. The authors in [41] described the proposal in more detail. Table 4 shows the parameters used to run the algorithm. In the first phase (training stage), drivers completed the route 300 times. An area was classified as inefficient when 70 percent of the time the driver drove inefficiently (210 times). Time frame was 10 seconds. This means that the driver was evaluated every 10 seconds using the previously described fuzzy logic system.

The algorithm was validated using 10 fold cross validation. The proposal is able to predict if the driver will perform inefficient actions by 91.81 percent on route $\mathrm{A}, 88.98$ percent on route B, and 90.14 percent on route C. These results were obtained taking into account the percentage of correctly classified instances for each driver.

\subsection{Detecting Traffic Incidents}

Events such as traffic accidents, vehicle breakdowns and adverse weather conditions directly influence the fuel consumption and the emission of gaseous pollutants. The impact of these incidents depends on their duration and intensity. Moreover, the negative effects are accentuated in the case that the vehicle has to stop. According to several authors [46], [47], eliminating the stops that the vehicle has to perform is even more important than the accelerations and decelerations. In terms of fuel consumption, it is better to avoid stops even if having to previously accelerate sharply. In recent years, some manufacturers (Peugeot, BMW, Citroen, Ford, etc.) include Start/Stop systems, minimizing the impact of the stop on fuel consumption [48]. However, these solutions are usually offered as extra equipment.

Currently, there are services that provide information about traffic incidents. However, we have found that 8
TABLE 4

Parameters of Inefficient Regions Algorithm

\begin{tabular}{lc}
\hline Parameter & Value \\
\hline $\begin{array}{l}\text { Driver Samples for each driver } \\
\text { (training stage) }\end{array}$ & 300 \\
Filter Driver Samples for each driver & $70 \%$ \\
(training stage) & \\
Time Frame (training stage) & 10 seconds \\
Learning Rate (driving stage) & 0.5 \\
Momentum (driving stage) & 0.2 \\
Epoch & 500 \\
Prediction Distance & 130 meters \\
\hline
\end{tabular}

sometimes they do not warn about traffic events that affect traffic flow slightly and these incidents cause a major impact on fuel consumption. Normally, these solutions use sensors installed on the road. The number of available sensors could be very low, being unable to detect such events.

To solve the problem, we propose to detect anomalous events based on driving samples obtained by other users under similar conditions (time, day of the week, and vehicle). In this case, each vehicle acts as a sensor.

The first step is to retrieve driving samples from other users considering the time, day of the week, and vehicle characteristics. The Expectation-Maximization algorithm is employed to perform this task. The result is the training dataset. It is composed of driving samples captured when conditions were very similar to the current.

Then, C4.5 algorithm is run using as input variables: average vehicle speed, stop rate, maximum stop time, average stop time, average acceleration (negative and positive), number of decelerations, and positive kinetic energy.

C4.5 classifier obtains the probability that is happening an anomalous event on the road. However, we observed (during testing) that there are false positives when the driver has an inefficient driving profile. To avoid this problem, the final probability that an incident is taking place depends on the probability obtained by $\mathrm{C} 4.5$ algorithm and the driving score.

Driving score is calculated using a fuzzy logic system and driving samples obtained by the driver, whose output is a number normalized between 0 and 1 . A high score indicates that the user is efficient, and therefore, the result of the C4.5 algorithm is reliable. The input variables are: acceleration, deceleration, vehicle speed, engine speed, engine load, and positive kinetic power. The fuzzy rules were built considering the longitudinal dynamics of the vehicle.

In our assistant, the algorithm was trained with 300 samples for each route. 200 contain driving samples with traffic incidents while the rest was without incidents. The solution was validated using 10 cross validation. Table 5 captures the results validation. The detection rate (DR) is defined as the number of incidents detected by the algorithm divided by the total number of incidents occurring during the observation period. False Alarm Ratio (FAR) is defined as the number of false incidents detected by the algorithm divided by the total number of instances in which are not occurring incidents.

This solution allows us to notify the user in advance when there is traffic incident even if it is slight. The driver can change the route or adapt the vehicle speed in order to 
TABLE 5

Validation of Algorithm for the Detection of Inefficient Region

\begin{tabular}{lcc}
\hline Route & DR & FAR \\
\hline A & $92.22 \%$ & $3.5 . \%$ \\
B & $93.55 \%$ & $3.01 \%$ \\
C & $90.47 \%$ & $3.92 \%$ \\
\hline
\end{tabular}

avoid having to stop. If the driver slows down progressively, the traffic jam may finish before reaching the place where it is happening. Therefore, the proposal reduces the frequency of the accelerations and decelerations as well as their intensity.

\section{Post-Actions TIPS}

\subsection{Real-Time Advice}

The user needs to acquire knowledge in order to change the driving style. This knowledge can be obtained through simulators or eco-driving lessons. The problem of this type of solutions is that the driver has to remember the eco-driving rules after that in order to apply them when driving. The solution monitors the driver behavior using the OBD2 port and notifies him or her when it detects some inefficient actions. The objective is that the user does not make the same errors again. The system warns when engine speed is high, vehicle speed is high, the accelerations (positive and negative) are sharply or the percentage of time driving at constant speed is too low.

There are already many similar proposals for eco-driving assistants in literature. However these systems do not take into account the prior driving style of the user and the particular characteristics of each vehicle. They employ the same thresholds in the eco-driving rules for all users. For example, there eco-driving assistants that warn the drivers when the accelerations are higher than $2 \mathrm{~m} / \mathrm{s}^{2}$. These values are not optimal and could also cause frustration in the drivers. We describe how we personalize the recommendations in the section "Customizing the eco-driving advice".

\subsection{Gamification}

The interest in fuel consumption in vehicles is recent. Until a few years ago, fuel consumption was not a decisive element in the purchase of a vehicle. The drivers had as priority elements the price and power. However, recent surveys indicate that consumption has become one of the most important factors in the choice of a vehicle [49]. According to several studies, this growing interest is linked to the increase in the price of fuel. However, this factor is not considered enough to motivate drivers [50].

Our proposal uses several elements of the gamification to encourage users in order to comply with the recommendations. As we saw in the introduction, this technique is based on using elements of games such as the challenge, the competitiveness and the progression in a different context. This improves the user's response to perform difficult or arduous tasks. In our case, the system provides the following feedback when the driver completes the trip:

Score. It depends on driving style. If the user follows the eco-driving rules, he or she will get a high score (see 9
Section 6). This value can be compared with other users. There is only a ranking because the rules employed to assess the drivers takes into account the particular characteristics of each driver, vehicle, and scenario.

Green house gases and fuel consumption. Driver can compare the result with the value obtained in other similar journeys (road type, weather, and traffic) made in the last month.

Badges. They are an important element for many people in order to encourage them to save fuel and motivate them to continually use the eco-driving assistant. This method has a positive impact on the user to reach a pre-set of objectives and is based on the concept of "status". Thresholds to unlock achievements are not the same for each user. They are calculated using the method described on the section "Customizing the eco-driving advice" in order to avoid that the user is discouraged.

\section{Driver Profile}

One of the keys to improve the driving style from the point of view of energy efficiency is to have a solution that objectively evaluates the driving in order to provide feedback to the driver. Evaluation of driving is a complex task since it depends on parameters that are independent of the driver behavior such as the road type, road conditions, and vehicle model. Therefore, direct comparison between drivers can produce inaccurate results. We propose to use a fuzzy logic system for the assessment of the driving. Fuzzy logic allows us to manage specifications with vague information. Unlike the traditional logic, fuzzy logic defines degrees of truth and falsehood similar to human behavior.

The structure of fuzzy logic systems consists of input variables, output variables and rules. The input variables are as follows: acceleration, deceleration, vehicle speed, engine speed, and engine load. The rules have been obtained through observation of real samples.

- IF acceleration IS (soft or hard) AND deceleration IS soft THEN score is efficient:

- IF acceleration IS hard AND deceleration IS hard THEN score is inefficient:

- IF engine speed IS high and engine load is (low or high) and vehicle speed IS (low or normal) THEN score IS inefficient:

- IF engineSpeed IS low and engine load is normal THEN score IS efficient

- IF vehicle speed IS high THEN score IS inefficient

The output is a number normalized between 0 and 10 . This value indicates the degree of compliance with the recommendations by the driver. If the score is high, the user is efficient. Otherwise, he or she is inefficient. The following scale is used to determine the user profile:

- $\quad$ 5: Aggressive Driver

- [5-7]: Normal Driver

- $\quad$ 7: Efficient Driver.

The fuzzy logic system is used for:

- Calculate the optimal average speed on a road section

- Get the best close driver

- Discover regions where users drive inefficiently on regular routes 
TABLE 6

Color Code Used in the User Interface

\begin{tabular}{lc}
\hline Color & Meaning \\
\hline Green & Efficient Driving \\
Yellow & Normal Driving \\
Red & Inefficient Driving \\
\hline
\end{tabular}

- Detect traffic incidents

- Customize the efficient driving tips

- Provide feedback (Gamification).

\section{Customizing the Eco-Driving Advice}

Eco-driving techniques are based on the driver behavior to reduce fuel consumption. The main advantage of this solution is that it is valid for any vehicle regardless of its technology. However, its effectiveness depends on the will of the user.

Efficient driving rules must be adapted for each type of user in order to avoid the discouragement of the driver. Otherwise, the user may not use the proposal. The thresholds of the eco-driving rules should not be the same for a normal driver than for an aggressive driver, e.g.: if there is an eco-driving rule such as "the vehicle speed cannot be higher than $100 \mathrm{~km} / \mathrm{h}^{\prime \prime}$, it is likely that the normal driver will follow it, but not the aggressive driver. In this case, a speed limit of $110 \mathrm{~km} / \mathrm{h}$ would be better for the aggressive driver. In conclusion, the change in driving style should be progressively applied in order to prevent the abandonment of the system.

On the other hand, we must bear in mind that the impact of accelerations, decelerations, vehicle speed and engine speed depend on the vehicle characteristics. For example, the impact of vehicle speed on fuel consumption is lower in modern vehicles than old cars due to aerodynamic improvements.

Finally, the driving style is also influenced by the road type. On an urban road, it is normal that the diver has to increase the frequency and intensity of the accelerations (positive and negative) in comparison with a highway. This increase happens due to traffic signs that force the driver to stop or the presence of other vehicles or pedestrians using the road. In this case, the thresholds of the eco-driving rules should be more permissive.

In this paper, we propose to estimate the thresholds of the rules based on the telemetry of other vehicles that have similar characteristics. We also take into account the driver profile (see Section 6), the road type and traffic conditions. The procedure is as follows:

1 Retrieve driving samples obtained in the same road type (motorway, urban road or conventional road) and under the similar traffic conditions.

2. Run Expectation-maximization algorithm in order to group the driving samples and assign the user one of the groups. The criteria to build clusters are as follows: vehicle weight, fuel consumption provided by the manufacturer, power engine, front surface, drag coefficient, and driving score (see Section 6).

3. Choose the " $n$ " driving samples with lower fuel consumption from the driver cluster.

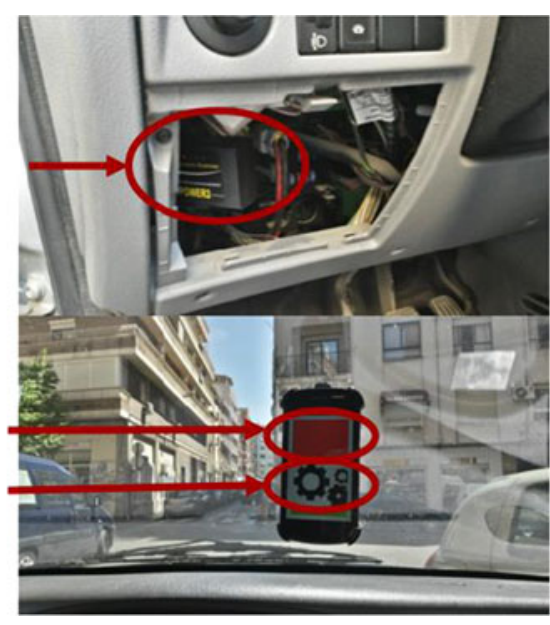

Fig. 5. Driving assistant installation and its user interface.

4. Calculate the median for each variable of the driving sample.

5. Select the third quartile taking into account all median values from driving samples. That number will be the threshold.

\section{USER INTERFACE}

The communication interface from the eco-driving assistant is very important. Distractions due to the manipulation of devices such as GPS receivers or mobile phones are the cause of a large number of accidents [51]. When designing an in-vehicle information system it is important to ensure that the recommendations and the method to convey these tips do not negatively affect cognitive processing and driving performance [52]. The eco-driving assistant has to be as less intrusive as possible. Instructions using voice output are less distracting and more usable than those systems presenting the information on a visual display [53]. However, an accurate speech recognizer and a clear voice user interface are necessary [52].

Our Android app (eco-driving assistant) uses voice output such as "Release throttle", "Shift gears" or "Press the brake pedal" during the driving. The driving score, incentives and achievements are shown on the mobile screen when the trip finishes. In addition, the driver can match their results with others users when the vehicle is stopped. The gamification system is implemented using Google Play Services.

On the other hand, the user interface is divided into two parts during the driving. The top notifies the user about the efficiency of the driving using a color code (Table 6). The bottom shows an image related to the eco-driving advice such as: traffic signs, traffic incidents, optimal vehicle speed on the road section, and vehicle speed of the best close driver. This user interface is very simple in order to avoid an increase in the cognitive load from the driver. Fig. 5 captures where is set the mobile phone, the devices that we need to run the driving assistant, and the user interface.

\section{System Evaluation}

In order to evaluate the energy savings achieved when using the proposed eco-driving assistant, 2,250 test drives 10 have been performed, using three different models of 
TABLE 7

Characteristics of the Vehicles

\begin{tabular}{lccccc}
\hline Route & Vehicle & $\begin{array}{c}\text { Weight } \\
(\mathrm{Kg})\end{array}$ & $\begin{array}{c}\text { Torque } \\
(\mathrm{Nm})\end{array}$ & $\begin{array}{c}\text { Engine } \\
\text { Power }\end{array}$ & $\begin{array}{c}\text { Average Fuel } \\
\text { Consumption } \\
(1 / 100 \mathrm{Km})\end{array}$ \\
\hline $\mathrm{A}, \mathrm{D}$, & Citroën & 1,313 & 240 & $110 \mathrm{CV}$ & 4.9 \\
$\mathrm{E}$ & Picasso & & & & \\
$\mathrm{B}$ & Citroen C5 & 1,486 & 320 & $138 \mathrm{CV}$ & 6 \\
$\mathrm{C}$ & Ford Fusion & 1,157 & 127 & $80 \mathrm{CV}$ & 6.5 \\
\hline
\end{tabular}

vehicles with 25 different drivers. All drivers had a long driving experience. They were voluntary and did not have knowledge of technology and eco-driving. Table 7 captures some details related to vehicles in the experiment.

Tests were made under similar conditions (time, weather, and traffic) in five different regions of Spain: Madrid (route A, D, and E), Seville (route B), and Granada (route C). Routes have urban road, secondary road and highway. The drivers completed the route 90 times. Each driver followed the route, 30 laps using the advices provided by the eco-driving assistant, 30 laps without using the assistant, and 30 laps employing the assistant and the gamification tools. In order to define a counter-balanced experiment, driving tests were divided into three phases: Driving using the assistant, driving using the assistant and gamification tools, and driving without assistant. The order of the stages changes randomly for each driver. All drivers completed 30 laps in each phase.

The solution was deployed on a Galaxy Nexus [54] mobile devices equipped with an ArmV9 processor at 1.2 GHz, $1 \mathrm{~GB}$ of RAM and Android 4.1.2. The OBDLink OBD Interface Unit [16] from ScanTool.Net was used to get the relevant data from the internal vehicle's CAN bus. The OBDLink OBD Interface Unit contains the STN1110 chip that provides an acceptable sample frequency for the system. In our tests, we obtain two samples per second.

In the following sections, we are going to analyze the impact of the proposal on the driving style and fuel consumption. The objective is to demonstrate that the ecodriving assistant helps the driver to adopt a more efficient driving style, minimizing the fuel consumption.

\subsection{Accelerations}

Fig. 6 captures the percentage of time that the drivers were speeding up and slowing down on routes A, B, C, D, and E. The use of the eco-driving assistant maximizes the time driving at constant speed. The solution notifies the user about nearby events that may force to slow down or stop. Also, it indicates the optimal speed from the point of view of energy efficiency. These recommendations avoid unnecessary energy demands. Accelerations were reduced by 11.56 percent on route $A, 15.10$ percent on route $B, 5.65$ percent on route $C, 7.55$ percent on route $D$, and 9.32 percent on route $\mathrm{E}$ when drivers employed the assistant along with gamification tools. The percentage of improvement is less without this type of feedback. In this case, accelerations were minimized by reduced by 2.34 percent on route $\mathrm{A}$, 1.89 percent on route $B, 4.49$ percent on route $C, 7.16$ percent on route $\mathrm{D}$, and 9.30 percent on route $\mathrm{E}$.

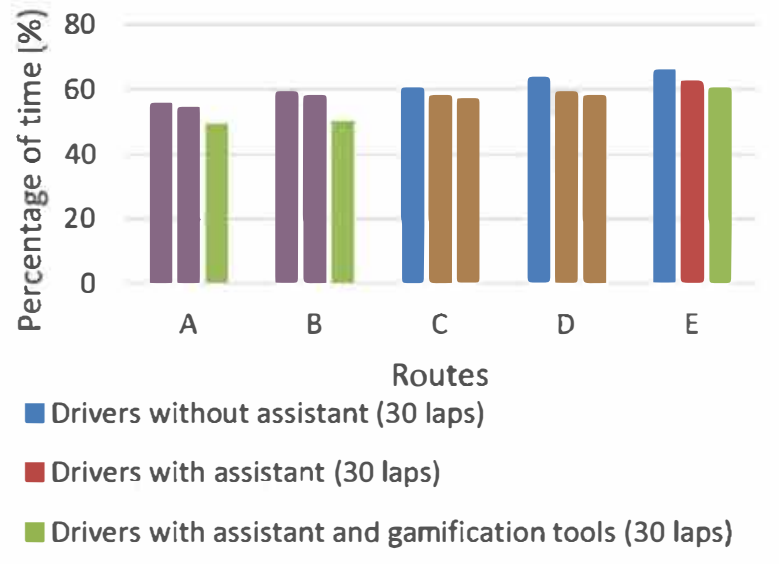

Fig. 6. Percentage of time which drivers are accelerating (positive and negative) on each route.

\subsection{Positive Kinetic Energy}

This variable measures the aggressiveness of driving and depends on the frequency and intensity of positive acceleration. A low value means that the driver is not aggressive. We can find more information about metrics used to measure the smoothness of driving in [34], [35], and [36]. PKE is calculated using the following equation:

$$
P K E=\frac{\sum\left(v_{i}-v_{i 1}\right)^{2}}{d}
$$

where $v_{i}$ is the vehicle speed (meters/seconds) and $d$ is the trip distance (meters).

Fig. 7 captures the PKI values obtained in each of the routes. Figure shows that the drivers minimize the PKI value by 14.37 percent on route $A, 36.72$ percent on route $B$, 27.99 percent on route $C, 30.22$ percent on route $D$, and 24.82 percent on route $\mathrm{E}$ when drivers employed the assistant along with gamification tools. The percentage of improvement is less without this type of feedback. In this case, standard deviation were improved by 9.14 percent on route $A, 4.38$ percent on route $B$, and 15.84 percent on route $C, 17.60$ percent on route $D$, and 20.99 on route $E$.

\subsection{Fuel Consumption}

Fig. 8 captures the fuel consumption of two drivers who drove on the route A for four months. Drivers completed

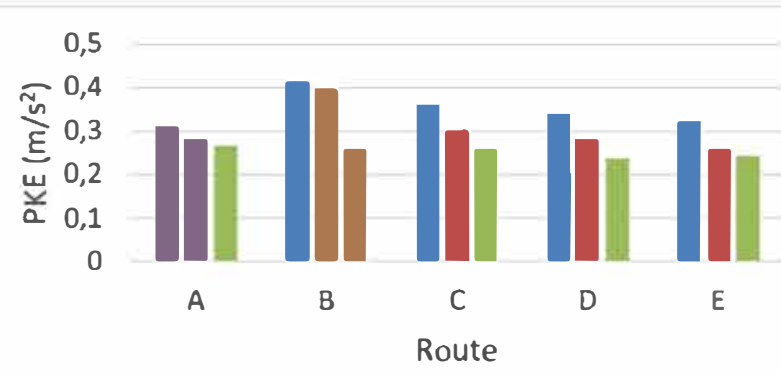

Drivers without assistant (30 laps)

Drivers with assistant (30 laps) 


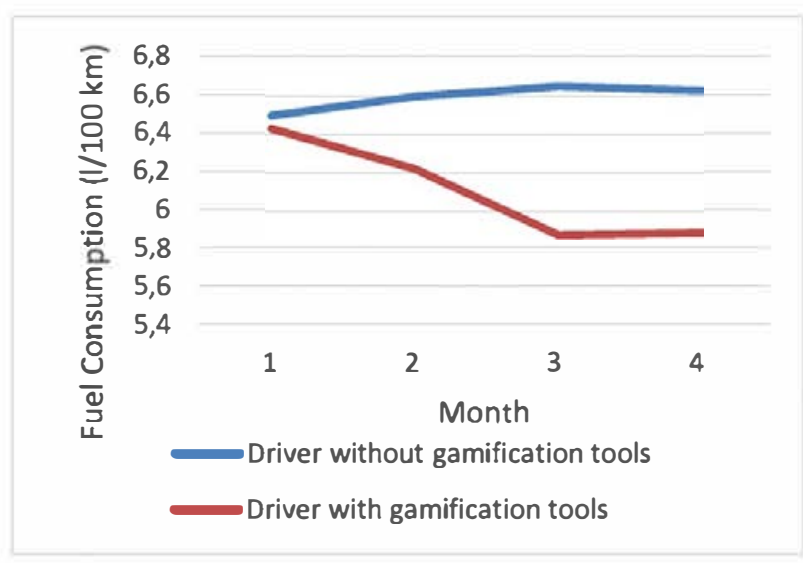

Fig 8. Average fuel consumption $(\mathrm{V} 100 \mathrm{~km})$ obtained by two drivers on route $A$ for four months.

the route from Monday to Friday starting at 8:30 a.m (5 laps per week). Both drivers had activated the driving assistant. However, one of the drivers did not have the gamification tools (blue line). We can see that the fuel consumption was similar during the first month. However, in the remaining months, driver without gamification worsens the fuel consumption while the other driver saves even more fuel. Fig. 9 captures the fuel consumption of two drivers during the first month. In the first weeks the evolution is similar. But from the fourth week, the driver without gamification returns to his previous driving style and increases the energy demand.

Fig. 10 shows the average fuel consumption obtained by the drivers on each route. Fuel consumption was reduced by 11.04 percent on average when drivers employed the assistant with the gamification tools. However, the improvement was lower (only 3.83 percent) when drivers did not have no incentives. In the latter case, there is even drivers on route $C$ who do not reduce fuel consumption significantly because they do not follow the recommendations of the driving assistant. These results show the importance of the gamification to keep the attention of the driver.

In order to validate that the energy savings obtained are not due to random factors, the t-test [55] with a 95 percent confidence interval has been used. We consider the null hypothesis as: "there is no improvement in fuel

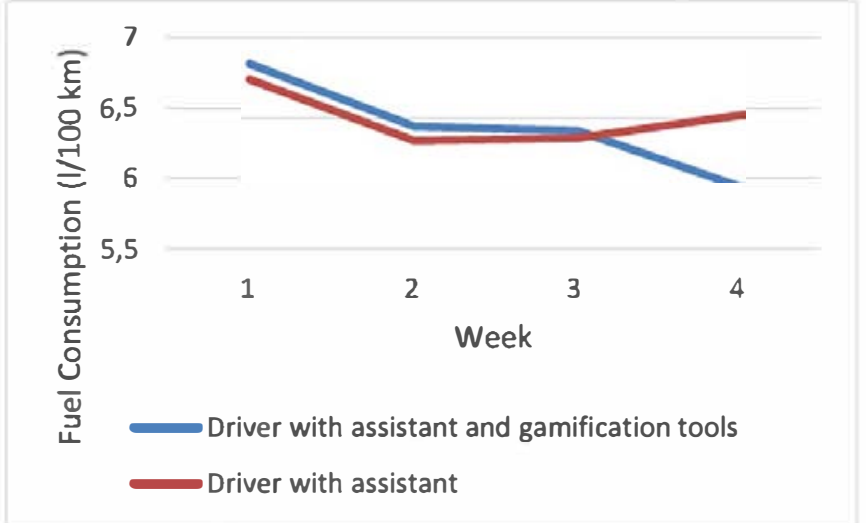

Fig. 9. Evolution of fuel consumption $(1 / 100 \mathrm{~km})$ oblained by two drivers on route $A$ in the first month using the driving assistant.

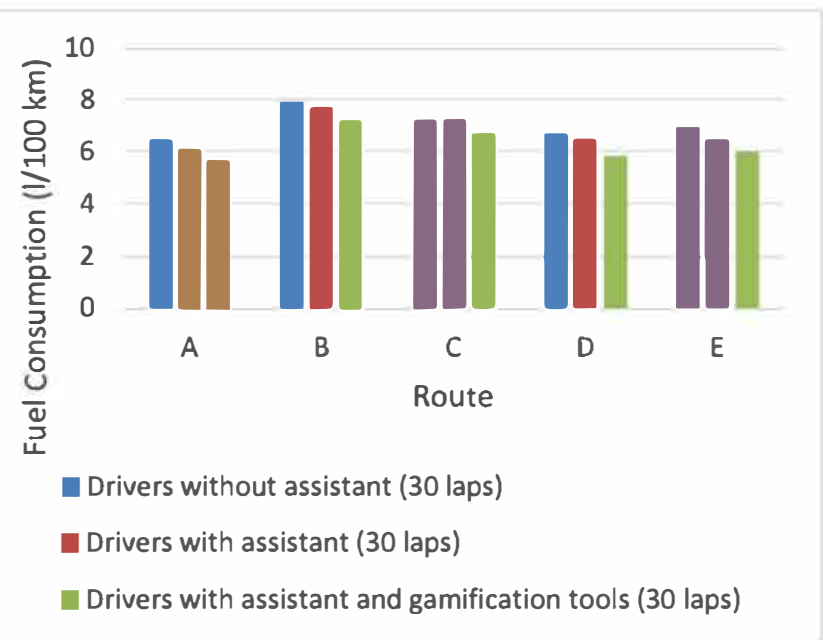

Fig. 10. Average fuel consumption ( $1100 \mathrm{~km})$ oblained by the drivers on each route.

consumption levels when using the eco-driving assistant. The p-value was lower than 0.05 in all cases. Therefore, the null hypothesis (under the 0.05 threshold) can be rejected and it demonstrates that the solution causes a clear improvement.

\subsection{Gamification}

Fig. 11 captures the score obtained by drivers. It is calculated using the fuzzy logic system described in the section "Driver Profile" (see Section 6). The value is between 0 and 10. A high value means that the driver is driving efficiently, maximizing the use of power generated by the engine. The results show that all drivers improve driving style from the point of view of energy saving and the emission of gaseous pollutants. However, we should highlight that fuel consumption may increase while the driver apply the eco-driving rules due to the road state.

Table 8 captures the number of drivers who earned each badge. Drivers with the game features enabled unlocked more achievements than users without the game features active. In addition, we can see as the main problem of the solution is to preserve the interest. For example, the majority of drivers completed a lap without accelerating sharply. On the contrary, the number of drivers who get 10 laps without accelerating sharply is much less. The use of the gamification mitigates this problem.

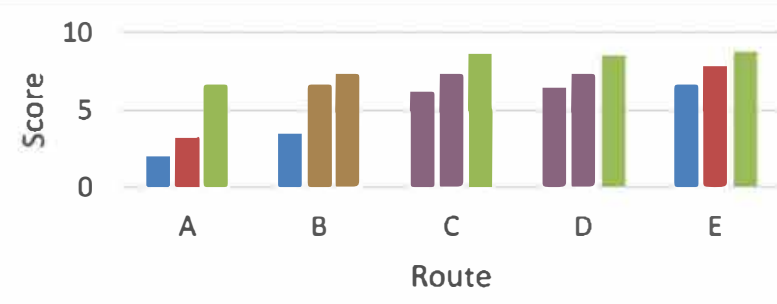

Without assistant
With assistant (gamification tool disabled)
With assistant (gamification tool enabled) 
TABLE 8

Number of Drivers Who Earned Badge

\begin{tabular}{|c|c|c|c|}
\hline & $\begin{array}{l}\text { Without } \\
\text { Assistant }\end{array}$ & $\begin{array}{l}\text { With } \\
\text { Assistant }\end{array}$ & $\begin{array}{c}\text { With Assistant } \\
\text { and gamification } \\
\text { tools }\end{array}$ \\
\hline Obtain 5 points & 18 & 21 & 25 \\
\hline Obtain 7 points & 7 & 13 & 18 \\
\hline Obtain 10 points & 0 & 1 & 4 \\
\hline $\begin{array}{l}\text { Complete a lap } \\
\text { without acceler ating } \\
\text { sharply }\end{array}$ & 11 & 24 & 25 \\
\hline $\begin{array}{l}\text { Complete } 10 \text { lap } \\
\text { without acceler ating } \\
\text { sharply }\end{array}$ & 3 & 10 & 20 \\
\hline $\begin{array}{l}\text { Complete a lap } \\
\text { without deceler ating } \\
\text { sharply }\end{array}$ & 2 & 8 & 17 \\
\hline $\begin{array}{l}\text { Complete } 10 \text { lap } \\
\text { without decelerating } \\
\text { sharply }\end{array}$ & 0 & 2 & 14 \\
\hline $\begin{array}{l}\text { Complete a lap with } \\
\text { a low value of PKE }\end{array}$ & 5 & 14 & 25 \\
\hline $\begin{array}{l}\text { Complete } 10 \text { lap with } \\
\text { a low value of PKE }\end{array}$ & 2 & 5 & 25 \\
\hline $\begin{array}{l}\text { Complete a lap with a } \\
\text { low value of standard } \\
\text { deviation of vehicle speed }\end{array}$ & 5 & 10 & 17 \\
\hline $\begin{array}{l}\text { Complete } 10 \text { lap with a } \\
\text { low value of standard }\end{array}$ & 1 & 6 & 13 \\
\hline $\begin{array}{l}\text { deviation of vehicle speed } \\
\text { Avoid driving at high speed }\end{array}$ & 10 & 19 & 22 \\
\hline Avoid driving at high gear & 5 & 15 & 23 \\
\hline
\end{tabular}

\subsection{Trip Time}

Fig. 12 captures the average trip time on each route. Trip time increased by 3.17 percent when the drivers use the solution and by 3.67 percent when the gamification tools was enabled. Although trip time increases slightly when drivers employed the driving assistant, the improvement on safety and fuel consumption are more significant. In addition, there are cases where this variable does not worse nearly such as route $\mathrm{C}$. This happens because the driving assistant reduces the braking and stopping situations, especially on urban road. As future work, we want to add an option where the driver indicates the journey priority and the driving assistant adjusts the recommendations in order to optimize the trip time.

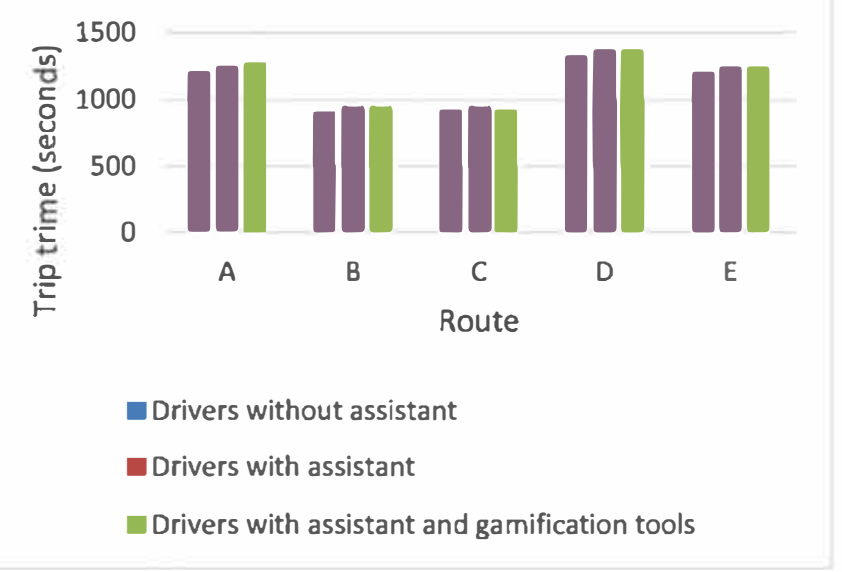

Fig. 12. Time trip for each route.
TABLE 9

Comparison of Features

\begin{tabular}{|c|c|c|c|c|}
\hline Ref. & $\begin{array}{l}\text { Advices fits } \\
\text { with driver } \\
\text { profile }\end{array}$ & $\begin{array}{c}\text { Anticipatory } \\
\text { Ad vices }\end{array}$ & $\begin{array}{c}\text { Methods to } \\
\text { encourage } \\
\text { the driver }\end{array}$ & $\begin{array}{c}\text { Validation } \\
\text { in real } \\
\text { environment }\end{array}$ \\
\hline [27] & $x$ & $x$ & V & V \\
\hline [28] & $x$ & V & $x$ & $x$ \\
\hline [29] & $x$ & V & $x$ & $x$ \\
\hline [30] & $x$ & V & $x$ & $x$ \\
\hline [31] & $x$ & V & $x$ & V \\
\hline [32] & $x$ & $x$ & $x$ & V \\
\hline [33] & V & $x$ & $x$ & $x$ \\
\hline [56] & $x$ & V & $x$ & $x$ \\
\hline [57] & $x$ & V & $x$ & $x$ \\
\hline [58] & $x$ & $x$ & $x$ & $x$ \\
\hline [59] & $x$ & $x$ & $x$ & V \\
\hline [60] & $x$ & V & $x$ & $x$ \\
\hline [61] & $x$ & V & $x$ & V \\
\hline [62] & $x$ & V & $x$ & V \\
\hline [63] & $x$ & V & $x$ & V \\
\hline $\begin{array}{l}\text { Our } \\
\text { solution }\end{array}$ & V & V & V & V \\
\hline
\end{tabular}

\subsection{Comparison with Other Solutions}

Table 9 captures the characteristics of other similar proposals. Table 10 performs a comparison of the performance. We have considered travel time and fuel consumption to evaluate the proposals. In addition, this table shows the price and if the driver has to modify the vehicle. We can observe that our system gets a good performance in comparison with other solutions where the fuel consumption or the travel time is worse.

Although there are some solutions that have better results [29], [63], they require modifications in the vehicle and have a high cost. The drivers are very reluctant to install third-party hardware in their vehicles. On the other hand, these proposals are usually validated using a driving simulator [30]. As the authors noted in [27], the results will probably be worse in real conditions (with traffic and more variability in the driving conditions).

TABLE 10

Comparison of Performance, Price, and Hardware Requirements

\begin{tabular}{|c|c|c|c|c|}
\hline Ref. & Travel Time & $\begin{array}{c}\text { Fuel } \\
\text { Consumption }\end{array}$ & Price & $\begin{array}{c}\text { Hardware } \\
\text { Requirement }\end{array}$ \\
\hline [27] & $+25.61 \%$ & $30 \%$ & Low & No \\
\hline [28] & N/A & $11.96 \%$ & High & Yes \\
\hline [29] & $+3.33 \%$ & 17.15 & High & Yes \\
\hline [30] & $+2.53 \%$ & $12.97 \%$ & Low & No \\
\hline [31] & N/A & $7 \%$ & Low & No \\
\hline [32] & $\mathrm{N} / \mathrm{A}$ & $7 \%$ & Low & No \\
\hline [33] & N/A & N/A & Low & No \\
\hline [56] & $+4.1 \%$ & $10.3 \%$ & Low & No \\
\hline [57] & N/A & $10.5 \%$ & Low & No \\
\hline [58] & $\mathrm{N} / \mathrm{A}$ & $16 \%$ & Low & Yes \\
\hline [59] & $N / A$ & $11 \%$ & Low & Yes \\
\hline [60] & +17.3 & $20.46 \%$ & Low & No \\
\hline [61] & $+6 \%$ & $13 \%$ & Low & No \\
\hline [62] & $+8.55 \%$ & $7.55 \%$ & High & Yes \\
\hline [63] & $+5 \%$ & $20 \%$ & High & Yes \\
\hline $\begin{array}{l}\text { Our } \\
\text { solution }\end{array}$ & $+3.67 \%$ & $11.04 \%$ & Low & No \\
\hline
\end{tabular}




\section{CONCLUSIONS AND FUtURE WORK}

In this paper, we have proposed an eco-driving assistant to support the learning of eco-driving techniques. The proposal also provides information in advance to prevent likely upcoming inefficient actions. We have analyzed the major causes that increase fuel consumption and we have proposed different control strategies to minimize their impact. The result of these models is a set of eco-driving tips.

The main contribution of this work is that in order to select the driving tips that will maximize the impact on the driver's energy efficiency we take into account the user profile, the road conditions, and the characteristics of the vehicle. Other proposals use the same advice for all types of users and situations. Therefore, the recommendations may not be optimal. In addition, a high exigency level could cause the user to ignore recommendations and turn off the system. Furthermore, the driving assistant uses gamification to encourage users to follow the recommendations. This technique avoids the driver returns to his or her previous driving style.

The results show an improvement in all the variables related to the driving style: acceleration, deceleration, engine speed and positive kinetic energy. We have also observed a reduction in the fuel consumption of up to $1.5 \mathrm{l} /$ $100 \mathrm{~km}$. However, the percentage of savings is also influenced by the road state. It may eventually happen that fuel consumption is higher when the driver is adopting an efficient driving style if road conditions (weather and traffic) worsen significantly.

As future work, we want to find out driver mood based on changes in the driving. For example, if the driver entered the opposite lane and increases the frequency of the accelerations and decelerations, it could mean that it is tired. In addition, we want the tips issued by the driving assistant to take into account the health habits from the driver. For example, if the driver has not walked regularly and there are many vehicles parked at the destination, the solution could suggest that he or she parks in a faraway place and finish the trip walking. This solution would reduce the fuel consumption and at the same time improve the health of the driver.

\section{ACKNOWLEDGMENTS}

The research leading to these results has received funding from the "HERMES-SMART DRIVER" project TIN201346801-C4-2-R within the Spanish "Plan Nacional de I+D+I" under the Spanish Ministerio de Economía y Competitividad and from the Spanish Ministerio de Economía y Competitividad funded projects (co-financed by the Fondo Europeo de Desarrollo Regional (FEDER)) IRENE (PT-2012-1036370000), COMINN (IPT-2012-0883-430000), and REMEDISS (IPT-2012-0882-430000) within the INNPACTO program.

\section{REFERENCES}

[1] A. Gorz. (2015, Jul.). "The social ideology of the motorcar," Le Sauv age September October, 1973, [Online]. Available: http://www. copenhagenize.com/2009/11/social ideology of motorcar.html

[2] M. Ichiyo, "Class struggle and technological innovation in Japan since 1945," Int. Inst. Res. Edu., Amsterdam, p. 47, 1987.

[3] F. Caiazzo, A. Ashok, I. A. Waitz, S. H. Yim, and S. R. Barrett, "Air pollution and early deaths in the United States. Part I: Quantifying the impact of major sectors in 2005," Atmospheric Environ., vol. 79, pp. 198 208, 2013.
[4] J. Barbé and G. Boy, “On board system design to optimize energy management," presented at the Eur. Annu. Conf. Human Decision Making Manual Control, Valenciennes, France, Sep. 2006.

[5] O. H. Koskinen, "Improving vehicle fuel economy and reducing emissions by driving technique," presented at the 15th ITS World Congress, New York, NY, Nov. 2008.

[6] C. C. Rolim, P. C. Baptista, G. O. Duarte, and T. L. Farias, "Impacts of on board devices and training on light duty vehicle driving behavior," Procedia Social Behavioral Sci., vol. 111, no. 5, pp. 711 720, Feb. 2014.

[7] M. Rutty, L. Matthews, J. Andrey, and T. Matto, "Eco driver training within the City of Calgary's municipal fleet: Monitoring the impact," Transp. Res. Part D: Transport Environ., vol. 24, pp. 44 51, Oct. 2013.

[8] B. Beusen, S. Broekx, T. Denys, C. Beckx, B. Degraeuwe, M. Gijsbers, K. Scheepers, L. Govaerts, R. Torfs, and L. I. Panis, "Using on board logging devices to study the longer term impact of an eco driving course," Transp. Res. Part D: Transport Environ., vol. 14, no. 7, pp. 514 520, Oct. 2009.

[9] R. Ando, Y. Nishihori, and D. Ochi, "Development of a system to promote eco driving and safe driving," in Proc. Smart Spaces Next Generation Wired/Wireless Netw., 2010, vol. 6294, pp. 207218.

[10] Y. Sabooh and H. Farzaneh, "Model for developing an eco driving strategy of a passenger vehicle based on the least fuel con sumption," Appl. Energy, vol. 86, no. 10, pp. 1925 1932, 2009.

[11] M. A. S. Kamal, M. Mukai, J. Murata, and T. Kawabe, "On board eco driving system for varying road traffic environments using model predictive control," in Proc. IEEE Int. Conf. Control Appl., Sep. 2010, pp. 16361641.

[12] C. P. Rommerskirchen, M. Helmbrecht, and K. J. Bengler, "The impact of an anticipatory eco driver assistant system in different complex driving situations on the driver behavior," IEEE Intell. Transp. Syst. Mag., vol. 6, no. 2, pp. 45 56, Summer 2014.

[13] T. Onoda, "IEA policies G8 recommendations and an afterwards," Energy Policy, vol. 37, no. 10, pp. 3823 3831, 2009.

[14] K. Erenli, "The impact of gamification: A recommendation of sce narios for education," in Proc. 15th Int. Conf. Interactive Collabora tive Learn., Sep. 2012, pp. 18.

[15] B. Jose, A. Fatma, Z. Nazar, and N. Tony, "Emo bin: How to recy cle more by using emoticons," in Proc. 8th ACM/IEEE Int. Conf. Human Robot Interaction, Mar. 2013, pp. 397397.

[16] F. Li Law, M. Kasirun, and Z. Chun Kiat Gan, "Gamification towards sustainable mobile application," in Proc. 5th Malaysian Conf. Softw. Eng., Dec. 2011, pp. 349353.

[17] (2015). INNOV 8 [Online]. Available: http://www 01.ibm.com/ software/solutions/soa/innov8/index.html

[18] (2015). OBD2 Adapter [Online]. Available: http://www.scantool. net/

[19] S. Godavarty, S. Broyles, and M. Parten, "Interfacing to the on board diagnostic system," in Proc. IEEE VTS Fall 52nd Veh. Tech nol. Conf., 2000, vol. 4, pp. 20002004.

[20] Vehicle Diagnostic Test Modes, SAE Standard SAE J1979, Apr. 30, 2002.

[21] A. Rousseau, and Y. Ding, "Impact of worldwide test procedures on advanced technology fuel efficiency benefits," in Proc. World Electric Vehicle Symp. Exhib., Nov. 2013, pp. 18.

[22] IDAE. Institute for the diversification and energy saving, "Efficient driving manual for tourism vehicles," 2007.

[23] S. Pumrin and D. J. Dailey, "Vehicle image classification via expectation maximization algorithm," in Proc. Int. Symp. Circuits Syst., May 2003, vol. 2, pp. II 468 II 471.

[24] L. Zadeh, "Fuzzy sets," Inf. Control, vol. 8, no. 3, pp. 338 353, 1965.

[25] B. Widrow and M. E. Hoff, "Adaptive switching circuits," in Proc. WESCOM Conv. Rec., pt. 4, 1960, pp. 96140.

[26] P. Viola and J. Michael, "Robust real time object detection," pre sented at the 2nd Int. Workshop Statistical Comput. Theories Vis. Model., Learn., Comput. Sampling, Vancouver, BC, 2001.

[27] O. Orfila, G. S. Pierre, and M. Messias. (2015, May 18). An android based ecodriving assistance system to improve safety and effi ciency of internal combustion engine passenger cars, Transporta tion Research Part C: Emerging Technologies [Online]. Available: http://dx.doi.org/10.1016/j.trc.2015.04.026

[28] H. Chaudhuri, B. Vahidi, and A. Pisu Pierluigi, "A fuel economic model predictive control strategy for a group of connected vehicles in urban roads," in Proc. Am. Control Conf., Jul. 2015, pp. 27412746.

[29] M. Staubach, N. Schebitz, F. Koster, and D. Kuck, "Evaluation of an eco driving support system," Transp. Res. Part F: Traffic Psychol. Behaviour, vol. 27, pp. 11 21, Nov. 2014. 
[30] T. Bar, R. Kohlhaas, J. M. Zollner, and K. Scholl, “Anticipatory driv ing assistance for energy efficient driving," in Proc. IEEE Forum Integr. Sustainable Transp. Syst., Jun. 29, 2011 Jul. 1, 2011, pp. 16.

[31] W. Y. Chou, Y. C. Lin, Y. H. Lin, and S. Y. Chen, "Intelligent eco driving suggestion system based on vehicle loading model," in Proc. 12th Int. Conf. ITS Telecommun., Nov. 2012, pp. 558562.

[32] A. Rionda, X. G. Paneda, R. García, G. Díaz, D. Martínez, M. Mitre, D. Arbesú, and I. Marín, "Blended learning system for efficient pro fessional driving," Comput. Educ., vol. 78, pp. 124 139, Sep. 2014

[33] E. Gilman, A. Keskinarkaus, S. Tamminen, S. Pirttikangas, J. Roning, and J. Riekki. (2015, Mar. 9). Personalised assistance for fuel efficient driving, Transp. Res. Part C: Emerging Technol. [Online]. Available: http://dx.doi.org/10.1016/j.trc.2015.02.007

[34] (2015). DGT [Online]. Available: http://infocar.dgt.es/etraffic/rss todas.xml

[35] (2015). AEMET [Online]. Available: http://www.aemet.es/es/ portada

[36] V. C. Magana and M. M. Organero, "Algoritmo para el cálculo de la velocidad media óptima en una ruta (ASGA)," Revista Iberoa mericana de Automática e Informática Industrial RIAI, vol. 11, no. 4 pp. 435 443, Oct. Dec. 2014.

[37] C. R. Reeves and J. E. Rowe, Genetic Algorithms Principles and Per spectives: A Guide to GA Theory. New York, NY, USA: Springer, 2002.

[38] A Charnes, W. W Cooper, B. Golany, L. Seiford, and J. Stutz, "Foundations of data envelopment analysis for Pareto Koopmans efficient empirical production functions," J. Econometrics, vol. 30, nos. 1/2, pp. 91 107, Oct./Nov. 1985

[39] W. Cooper William, L. M. Seiford, and K. Tone, "Data Envelopment Analysis: A Comprehensive Text With Models, Applications, References and DEA Solver Software. 2nd ed. New York, NY, USA: Springer, 2007, p. 490.

[40] I. Ben Dhaou, "Fuel estimation model for ECO driving and ECO routing," in Proc. IEEE Intell. Veh. Symp., Jun. 2011, pp. 3742.

[41] V. Corcoba Magana and V. M. Munoz Organero, "Discovering regions where users drive inefficiently on regular journeys," IEEE Trans. Intell. Transp. Syst., vol. 16, no. 1, pp. 221 234, Feb. 2015.

[42] M. Munoz Organero and V. C. Magana, "Validating the impact on reducing fuel consumption by using an ecodriving assistant based on traffic sign detection and optimal deceleration patterns," IEEE Trans. Intell. Transp. Syst., vol. 14, no. 2, pp. 1023 1028, Jun. 2013.

[43] K. S. Nesamani and K. P. Subramanian, "Development of a driv ing cycle for intra city buses in Chennai, India," Atmospheric Envi ron., vol. 45, no. 31, pp. 5469 5476, Oct. 2011.

[44] R. J. Nairn, S. Partners, L Economic Consultants, and H. Watson, "Victorian transport externalities study 3. Strategies for reducing emissions of greenhouse gases and ozone precursors from land based transport," Rep. prepared for EPA, Melbourne, Vic., Aus tralia, 1994

[45] W. Frith and P. Cenek, "AA research: Standard metrics for trans port and driver safety and fuel economy," Opus Int. Consultants Central Laboratories, Nov. 2012.

[46] L. Evans, "Driver behavior effects on fuel consumption in urban driving humans factors," J. Human Factors Ergonomics Soc., vol. 21, pp. 4389 398, 1979.

[47] J. Gonder, E. Matthew, and S. Witt, "Analyzing vehicle fuel saving opportunities through intelligent driver feedback," SAE Techn. Paper, no. 201201 0494, 2012.

[48] J. Bishop, A. Nedungadi, G. Ostrowski, B. Surampudi, P. Armir oli, and E. Taspinar, "An engine start/stop system for improved fuel economy," SAE Techn. Paper, no. 200701 1777, 2007.

[49] J. Gillis y and M. Cooper, "On the road to 54 MPG: A progress report on achievability," Consumer Fed. America, 2013.

[50] A. Peters, P. D. Haanby, and R. W. Scholzc, "Understanding car buying behavior: Psychological determinants of energy efficiency," Int. J. Sustainable Transp., vol. 9, no. 1, pp. 59 72, 2015.

[51] Y. Dong, Z. Hu, K. Uchimura, and N. Murayana, "Driver inatten tion monitoring system for intelligent vehicles: A review," IEEE Trans. Intell. Transp. Syst., vol. 12, no. 2, pp. 596 614, Jun. 2011.

[52] M. Peissner, V. Doebler, and F. Metze. Can voice interaction help reducing the level of distraction and prevent accidents? Meta Study on Driver Distraction and Voice Interaction, White Paper, p. 24, May 2011.

[53] K. Young and M. Regan, "Driver distraction: A review of the liter ature," in Distracted Driving, I. J. Faulks, M. Regan, M. Stevenson, J. Brown, A. Porter, and J. D. Irwin Eds. Sydney, N.S.W., USA: Australasian College of Road Safety, 2007, pp. 379405.
[54] Google. (2013). Galaxy Nexus characteristics. [Online]. Available: http:/ / www.android.com/devices/detail/galaxy nexus

[55] J. O'Connor, J. Robertson, and F. Edmund. (1908). "Student's t test," MacTutor History of Mathematics archive, Univ. St Andrews, St Andrews, U.K. [Online]. Available: http://www history.mcs.st andrews.ac.uk/Biographies/Gosset.html

[56] C. P. Rommerskirchen, M. Helmbrecht, and K. J. Bengler, "The impact of an anticipatory ECO driver assistant system in different complex driving situations on the driver behavior," IEEE Intell. Transp. Syst. Mag., vol. 6, no. 2, pp. 45 56, Summer 2014.

[57] R. Kohlhaas, T. Schamm, D. Nienhuser, and J. M. Zollner, "Anticipatory energy saving assistant for approaching slower vehicles," in Proc. 14th Int. IEEE Conf. Intell. Transp. Syst., Oct. 2011, pp. 19661971.

[58] M. Van Der Voort, M. S. Dougherty, and A. Martin van Maar seveen, "Prototype fuel efficiency support tool", Transp. Res. Part C: Emerging Technologies, vol. 9, no. 4, pp. 279 296, Aug. 2001.

[59] M. C. Van Der Voort, "FEST. A new driver support tool that reduces fuel consumption and emissions," in Proc. Int. Conf. Adv. Driver Assistance Syst., 2001, pp. 9093.

[60] A. A. Malikopoulos and J. P. Aguilar, "Optimization of driving styles for fuel economy improvement," in Proc. 15th Int. IEEE Conf. Intell. Transp. Syst., Sep. 2012, pp. 194199.

[61] M. Barth and K. Boriboonsomsin, "Energy and emissions impacts of a freeway based dynamic eco driving system," Transp. Res. Part D: Transport Environ., vol. 14, no. 6, pp. 400 410, Aug. 2009.

[62] L. Nouveliere, S. Mammar, and H. T. Luu, "Energy saving and safe driving assistance system for light vehicles: Experimentation and analysis," in Proc. 9th IEEE Int. Conf. Netw., Sensing Control, Apr. 2012, pp. 346351.

[63] L. Kang, B. Qi, D. Janecek, and S. Banerjee, "EcoDrive: A mobile sensing and control system for fuel efficient driving," in Proc. 21st Annu. Int. Conf. Mobile Comput. Netw., New York, NY, 2015, pp. 358371 . 